\title{
NAVUS indexada no Redalyc e na Web of Science: curva de aprendizado no processo editorial em revistas científicas
}

A inclusão de uma revista no ambiente científico é feita por meio de alguns mecanismos, sendo a indexação a mais relevante e também a mais procurada pelas revistas científicas (CAMPANARIO; SANTOS, 2011). A Navus se encontra indexada em várias bases de dados, portais e diretórios de periódicos, índices e catálogos, como pode ser visto no menu da revista, na opção SOBRE e INDEXAÇÃO. A principal base de dados brasileira da área da revista, que é a Administração Pública e de Empresas, Ciências Contábeis e Turismo, é a SPELL (Scientific Periodicals Electronic Library), onde a Navus está indexada.

A partir de julho de 2017, passamos a fazer parte do Redalyc (Red de Revistas Científicas de América Latina y el Caribe, España y Portugal), uma das mais conhecidas e importantes bases de dados internacionais. A indexação nessa base é utilizada como critério de agências de fomento brasileiras e internacionais, em seus editais de subsídios a periódicos científicos. O Redalyc é uma base de dados bibliográfica de acesso aberto, apoiada pela Universidade Autônoma do México, com a ajuda de inúmeras outras instituições de ensino superior. Desde a sua criação, seu objetivo é dar visibilidade à produção científica gerada na região ibero-americana. Atualmente, o Redalyc é um repositório de conhecimento consolidado, possuindo, por volta de 1.253 revistas científicas e 568.511 artigos completos indexados.

Em setembro de 2017 comemoramos a entrada da Navus na Web of Science, resultado de um processo iniciado em 2015, do qual já mencionamos no editorial do v6 n2. À medida que o nosso fator de impacto (relação do número de artigos com citações) veio crescendo, passamos a integrar automaticamente o Emerging Science Citation Index, mantido pela Thomson Reuters. Ao longo destes dois anos, seguindo a natureza da produção e comunicação científica, bem como a visibilidade de nosso periódico, os mecanismos de indexação automática da Web of Science passaram a apresentar 108 artigos publicados na Navus em sua base principal.

A Web of Science é a principal base de dados e indexadora existente. Mantida pela Clarivate Analytics, sua representatividade no Brasil torna os periódicos ali indexados com os melhores indicadores Qualis propiciados pela Coordenação de Aperfeiçoamento de Pessoal de Nível Superior (CAPES). Diferente dos demais indexadores, seu processo automático de indexação reflete a urgente demanda de acelerar e melhorar a comunicação científica, sem a necessidade de procedimentos burocráticos, acompanhando de maneira natural o modo como a ciência se comunica e se reproduz.

Figurar nestas bases de dados, pela representatividade internacional que elas possuem, significa também um prestígio para a Navus e um aspecto honroso para sua equipe editorial, autores, avaliadores e leitores.

Cada vez que a revista se submete a avaliação das bases de dados, aumenta a curva de aprendizado da equipe editorial que, para se adequar aos critérios por elas estabelecidos, acaba revendo suas políticas editoriais. 
Neste editorial queremos dividir com nossos autores, leitores, avaliadores e, principalmente nossos pares, editores de outras revistas, um pouco da curva de aprendizado que é, principalmente para os editores, o processo de indexação. Neste sentido, apontamos que, entre os critérios que devem ser atendidos pelas revistas científicas aos quais buscamos adequação estão:

- pontualidade na publicação que, em nosso caso, passou a ser o primeiro dia da periodicidade;

- explicitação da data de publicação de cada edição;

- política e critérios claros de avaliação dos manuscritos, descrevendo como são dirimidos os casos de controvérsia derivados do processo de avaliação;

- participação de avaliadores externos;

- equipe editorial composta por membros externos à instituição, tanto nacionais quanto internacionais;

- cobertura temática bem definida;

- publicação em mais de um formato, como pdf e html;

- ID dos autores, como por exemplo o ORCID (Open Researcher and Contributor ID);

- instruções aos autores em um segundo idioma;

- declaração de direito autoral na submissão do manuscrito.

A revista continua com uma importante parceria com o programa de pós-graduação em Engenharia e Gestão do Conhecimento da Universidade Federal de Santa Catarina, na publicação de alguns trabalhos oriundos do Congresso Internacional de Conhecimento e Inovação (CIKI), do qual temos um artigo publicado nesta edição, intitulado "Diagnóstico da inovação em empresas de tecnologia da informação de um município do sudoeste do Paraná".

Nesta edição ainda estamos publicando artigos com os seguintes temas:

- gestão por indicadores de desempenho em um shopping center;

- $\quad$ indicadores e mapeamentos de processos da Educação Superior;

- $\quad$ vantagem competitiva sustentável em empresas de software;

- gestão de prazo de entrega dos fornecedores de Instituições de Educação Superior (IES);

- teoria do comportamento planejado em jogos on-line;

- gestão do capital de giro no setor de cerâmica;

- gestão de pós-graduação em Administração.

Estamos publicando uma resenha do livro "Vertigem digital: por que as redes sociais estão nos dividindo, diminuindo e desorientando", como retomada às publicações de resenha, para qual convidamos os leitores a submeter novos trabalhos para as próximas edições.

Boa leitura!

Eli Lopes da Silva e Nadi Helena Presser

Editores

CAMPANARIO, M. A.; SANTOS, T. C. S. Escopo de projeto para indexação de revistas científicas. EccoS - Rev. Cient., São Paulo, n. 25, p. 251-272, jan./jun. 2011. 